\title{
Determination of age from the cadaver's skull-evidence from a cross-sectional study from central India
}

\author{
Gaurav Tiwari ${ }^{1}$, Avinash Thakur ${ }^{2, *}$, Murali Lalwani ${ }^{3}$ \\ ${ }^{1}$ Demonstrator, Bundelkhand Medical College, Sagar, Madhya Pradesh, ${ }^{2}$ Senior Resident, Dept. of Forensic Medicine and \\ Toxicology, All India Institute of Medical Sciences, Bhopal, Madhya Pradesh, ${ }^{3}$ Professor \& Head, Dept. of Forensic Medicine \\ and Toxicology, Gandhi Medical College, Bhopal, Madhya Pradesh, India
}

*Corresponding Author:

Email: dr.avinashthakur@gmail.com

\begin{abstract}
Introduction: Cranial suture closure is one trait that has been used since the 16 th century for age estimation after the 2 nd decade of life. To determine the pattern of cranial vault suture closure in relation to age among dead bodies of subjects (3rd to 5th decades of life) and identify any relationship between progression of the union of cranial suture and age.

Materials and Methods: We conducted a cross-sectional observational study from January 2016 to June 2017 involving 500 cadavers. Cadavers were studied for ectocranial and endocranial closure pattern for sagittal-coronal and lambdoid sutures. Spearman coefficient was utilized to assess the correlation between the age of the subject and the stage of fusion of cranial sutures.
\end{abstract}

Results: We noted that the process of endocranial fusion of cranial suture was more regular than ectocranial. The coronal suture was the first to fuse.

Conclusion: No definite correlation was found to exist between age and suture closures.

Keywords: Age, Skull, Cadaver, India.

\section{Introduction}

Every person tends to undergo change to various degrees during the course of their life; thus, no two individuals are ever alike in all their measurable characteristics. Identification is the determination of the individuality of a person based on certain physical and biological characteristics. ${ }^{1}$ It is an important aspect of civil, criminal, legal, and statistical investigations. ${ }^{1}$ Identification of an individual can be done by means of various parameters such as clothes, birthmarks, scar, tattoo marks, malformations, assessment of age and sex, determination of race and stature, anthropometric measurements, fingerprints, lip print, DNA fingerprinting etc., ${ }^{1,2}$

Age, sex, and stature are the main parameters which lend a hand in establishing the correct identity of any individual. In an unidentified person, the approximate age can be estimated by some physical parameters viz. height, weight, dental examination, and secondary sexual characteristics. ${ }^{3,4}$ In addition, gender can accurately assess by examining the sexual characteristics of male and female like gonads, build, breasts, pubic hair, body hair, gluteal region, etc. Stature can be estimated by following the standard procedures with the help of appropriate instruments. ${ }^{3,4}$ These measures are helpful only when the body is intact but when a mutilated, dismembered or skeletonized body is recovered, these parameters become a challenge to interpret. ${ }^{3,4}$ Furthermore, the task of identification becomes challenging when a dead body is found in advance stages of decomposition, dismembered (mutilated); burnt bodies or only skeletal remains are brought for forensic analysis. ${ }^{4,5}$
According to Krogman (1986)1, identification can be $100 \%$ accurate if the whole skeleton is available; $98 \%$ by combination of pelvis and skull; $95 \%$ by pelvis alone, $90 \%$ by skull alone and $80 \%$ by long bones. ${ }^{6}$ Skull has a unique skeletal structure in several ways; its origin as embryonic cellular form (neural crest), ossification (intramembranous and endochondrial) and flexibility (fibrous sutures). ${ }^{7,8}$ The cranial vault bones are formed by intramembranous ossification, while the bones of the base of the skull are formed by endochondrial ossification. ${ }^{7,8}$ The large flexible fibrous joints between cranial bones are termed as cranial sutures, which allow the head to pass through the birth canal and postnatal brain growth. ${ }^{7,8}$ The three important sutures are coronal, sagittal and lambdoid. ${ }^{9}$ The union timing of a suture is a helpful aid for age and sex determination whereas the length of suture helps in sex and stature estimation. ${ }^{9,10}$ Only a handful of studies have been conducted in India, and data on the heterogeneous population of Madhya Pradesh is very limited. Thus we conducted this study to determine the relationship between progressions of the union of the cranial suture with the age of the subject.

\section{Materials and Methods}

Study Design: This was a cross-sectional study.

Study Setting: The present study was conducted in the Department of Forensic Medicine and Toxicology, Gandhi Medical College, Bhopal, Madhya Pradesh.

Study Duration: The total duration of the study was eighteen months (January' 2016- June' 2017).

Study Subject: The study was undertaken on dead bodies coming for medico-legal examination to the 
Department of Forensic medicine, Gandhi Medical College, Bhopal.

\section{Inclusion Criteria}

1. The cases whose correct age was known before medicolegal postmortem examination; age was confirmed by documentary evidence like birth certificate, identification cards, ration card, etc.

2. Subjects of $\geq 20$ years of age.

\section{Exclusion Criteria}

1. Unidentified bodies, where exact age cannot be confirmed.

2. Cases with a severe head injury (on the basis of history and external examination), which may hamper the examination of suture closure.

3. Cases with any congenital or hereditary bony deformity on the basis of history and external examination.

4. Bodies in which

Sample Size: We collected data from 500 dead bodies.

\section{Data Collection}

The body was placed in a supine position on the autopsy table, with the neck and feet in a neutral position. The whole thickness of the scalp was incised with the help of a scalpel between the mastoid process over the vertex in the coronal plane. ${ }^{11-13}$ The anterior and posterior halves of the scalp were separated from the skull and then reflected forward and backwards. ${ }^{11-13}$ An incision made and then the soft tissues adherent to the periosteum along the coronal, sagittal, lambdoid sutures were scraped manually until the suture line over the vertex, the pterion on side, bregma, lambda and asterion on both sides were clearly visible. ${ }^{11-13}$ The length of coronal, sagittal, lambdoid sutures was measured using a non-extensible thread and Vernier calliper graduated in millimetres. Each side of the coronal suture was studied in two parts- upper (RU, LU) and lower (RL, LL). The sagittal suture was examined in three parts-anterior $1 / 3(\mathrm{~S} 1)$, middle $1 / 3$ (S2) and posterior 1/3 (S3). Each side of the lambdoid suture was studied in two parts- upper (R/L1) and lower $(\mathrm{R} / \mathrm{L} 2) .{ }^{11-13}$ The examination was done for inner and outer tables separately, less than 5 point scale of 0 to 4 i.e., "0- open, 1- less than one half closed, 2- half closed, 3- more than one half closed, 4- totally closed". ${ }^{11-13}$ Then mean was calculated for each component derived from all the subjects studied to know the pattern of suture closure.

\section{Data Analysis}

Descriptive analyses were conducted to study the distribution of dependent variables among study participants. $P$ value $<0.05$ was considered statistically significant. The sample was statistically analyzed using SPSS version 20.0. Appropriate statistical test(s) were applied for comparative data analysis.

\section{Ethical Clearance}

The present study was approved in the year 2016 by the ethical board on human research of the Gandhi Medical College, Bhopal.

\section{Results}

In our study, we observed that most study subjects were in the 20-29 years of age group. As can be inferred from table 1 the minimum age of subject was 20 years and the maximum age was 89 years, mean age was 38.07 years (standard deviation \pm 13.61 ) and the median age was 35 years.

Table 1: Distribution of study subjects based on their age and gender

\begin{tabular}{|c|c|c|c|c|c|c|}
\hline \multirow{2}{*}{ Age } & \multicolumn{2}{c|}{$\begin{array}{c}\text { Male } \\
(\mathbf{n 1 = 3 0 7})\end{array}$} & \multicolumn{2}{c|}{$\begin{array}{c}\text { Female } \\
(\mathbf{n 2 = 1 9 3})\end{array}$} & \multicolumn{2}{c|}{$\begin{array}{c}\text { Total } \\
(\mathbf{n = 5 0 0})\end{array}$} \\
\cline { 2 - 7 } & $\mathbf{n}$ & $\mathbf{\%}$ & $\mathbf{n}$ & $\mathbf{\%}$ & $\mathbf{n}$ & $\mathbf{\%}$ \\
\hline $20-29$ & 72 & 23.4 & 83 & 43 & 155 & 31 \\
\hline $30-39$ & 80 & 26 & 61 & 31.6 & 141 & 28.2 \\
\hline $40-49$ & 73 & 23.7 & 25 & 12.9 & 98 & 19.6 \\
\hline $50-59$ & 46 & 14.9 & 12 & 6.2 & 58 & 11.6 \\
\hline $60-69$ & 24 & 7.8 & 7 & 3.6 & 31 & 6.2 \\
\hline$>70$ & 12 & 3.9 & 5 & 2.5 & 17 & 3.4 \\
\hline \multicolumn{8}{|c|}{ Statistical parameters } \\
\hline $\mathrm{N}$ & Min & Max & Range & Mean & Median & SD \\
\hline 500 & 20 & 89 & 69 & 38.07 & 35 & 13.61 \\
\hline
\end{tabular}

(Table.2) depicts the comparison between the mean stage(s) of the union of ectocranial sagittal suture between males and females. We observed that males' shows mean of 2.54 whereas females' mean was 1.96. On applying the independent sample t-test; we concluded that the starting and complete closure of ectocranial sagittal suture occurred earlier in males as compared to females. 
Table 2: Distribution of study subjects based on gender and mean stage of the union of ectocranial and endocranial sagittal sutures

\begin{tabular}{|l|c|c|c|c|}
\hline \multirow{2}{*}{$\begin{array}{c}\text { Age } \\
\text { group }\end{array}$} & \multicolumn{2}{|c|}{ Ectosagittal } & \multicolumn{2}{c|}{ Endosagittal } \\
\cline { 2 - 5 } & $\begin{array}{c}\text { Male } \\
\text { Mean (SD) }\end{array}$ & $\begin{array}{c}\text { Female } \\
\text { Mean (SD) }\end{array}$ & $\begin{array}{c}\text { Male } \\
\text { Mean (SD) }\end{array}$ & $\begin{array}{c}\text { Female } \\
\text { Mean (SD) }\end{array}$ \\
\hline $20-29$ & $0.96(0.528)$ & $0.93(0.45)$ & $1.2(0.559)$ & $1.11(0.646)$ \\
\hline $30-39$ & $2.22(0.587)$ & $2.29(0.395)$ & $2.92(0.265)$ & $2.92(0.185)$ \\
\hline $40-49$ & $3.43(0.475)$ & $3.34(0.313)$ & $3.69(0.562)$ & $3.68(0.244)$ \\
\hline $50-59$ & $3.5(0.351)$ & $3.31(0.216)$ & $3.66(0.253)$ & $3.56(0.216)$ \\
\hline $60-69$ & $3.5(0.578)$ & $3.25(0.721)$ & $3.78(0.258)$ & $3.78(0.303)$ \\
\hline$>70$ & $3.22(0.757)$ & $3.35(0.627)$ & $3.58(0.624)$ & $3.8(0.209)$ \\
\hline \multicolumn{4}{|l}{ Independent t-test on gender versus closure of ectocranial sagittal suture was significant $(\mathrm{p}<0.001)}$. \\
\hline
\end{tabular}

(Table. 3) illustrates the results of the Spearman correlation coefficient between the mean stage of fusion of sutures and the age of study participants. We observed that ecto and endocranial sagittal suture shows a significant correlation in the age groups of 20-29 years, 30-39 years, 40-49 years and $>70$ years, and the groups which do not show significant correlation were 50-59 years and 60-69 years.

Right-sided coronal suture shows a significant correlation in the age groups of 20-29 years, 30-39 years, 40-49 years and 60-69 years, and the groups which do not show significant correlation were 50-59 years and $>70$ years. Left-sided coronal suture results were similar to right-sided coronal suture. Right-sided lambdoid suture shows a significant correlation in the age groups of 20-29years and 30-39years, and the groups which do not show significant correlation were 40-49 years, 50-59 ears, 60-69 years and >70 years. Left-sided lambdoid suture shows a significant correlation in the age groups of 20-29 years, 30-39 years and $>70$ years, and the groups which do not show significant correlation were 40-49 years, 50-59 years and 60-69 years.

Table 3: Spearman rank correlation coefficient and level of significance between the mean stage of the union of ecto and endocranial sutures in various age groups.

\begin{tabular}{|l|c|c|c|c|c|}
\hline $\begin{array}{c}\text { Age } \\
\text { group } \\
(\mathbf{N})\end{array}$ & $\begin{array}{c}\text { EctoS/ } \\
\text { EndoS } \\
\text { (Spearman Rank } \\
\text { correlation } \\
\text { Coefficient/ } \\
\text { Level of } \\
\text { Significance) }\end{array}$ & $\begin{array}{c}\text { EctoCR/ } \\
\text { EndoCR } \\
\text { (Spearman Rank } \\
\text { correlation } \\
\text { Coefficient/ } \\
\text { Level of } \\
\text { Significance) }\end{array}$ & $\begin{array}{c}\text { EctoCL/ } \\
\text { EndoCL } \\
\text { (Spearman Rank } \\
\text { correlation } \\
\text { Coefficient/ } \\
\text { Level of } \\
\text { Significance) }\end{array}$ & $\begin{array}{c}\text { EctoLR/ } \\
\text { EndoLR } \\
\text { (Spearman Rank } \\
\text { correlation } \\
\text { Coefficient/ } \\
\text { Level of } \\
\text { Significance) }\end{array}$ & $\begin{array}{c}\text { EctoLL/ } \\
\text { EndoLL } \\
\text { (Spearman Rank } \\
\text { correlation } \\
\text { Coefficient/ } \\
\text { Level of } \\
\text { Significance) }\end{array}$ \\
\hline $20-29$ & $0.616^{* *}$ & $0.597^{* *}$ & $0.641^{* *}$ & $0.654^{* *}$ & $0.679^{* *}$ \\
$(155)$ & $/ 0.000$ & $/ 0.000$ & $/ 0.000$ & $/ 0.000$ & $/ 0.000$ \\
\hline $30-39$ & $0.384^{* *}$ & $0.218^{* *}$ & $0.252^{* *}$ & $0.420^{* *}$ & $0.190^{* *}$ \\
$(144)$ & $/ 0.000$ & $/ 0.01$ & $/ 0.000$ & $/ 0.000$ & $/ 0.024$ \\
\hline $40-49$ & $0.216^{* *}$ & $0.307^{* *}$ & $0.454^{* *}$ & 0.152 & 0.104 \\
$(98)$ & $/ 0.033$ & $/ 0.002$ & $/ 0.000$ & $/ 0.134$ & $/ 0.31$ \\
\hline $50-59$ & 0.034 & 0.169 & 0.106 & 0.2 & 0.075 \\
$(58)$ & $/ 0.803$ & $/ 0.206$ & $/ 0.428$ & $/ 0.132$ & $/ 0.575$ \\
\hline $60-69$ & 0.02 & $0.514^{* *}$ & $0.358^{* *}$ & 0.045 & $/ 0.211$ \\
$(31)$ & $/ 0.915$ & $/ 0.003$ & $/ 0.048$ & 10.81 & 0.254 \\
\hline$>70$ & $0.559^{* *}$ & 0.255 & 0.253 & 0.411 & $/ 0.015$ \\
$(17)$ & $/ 0.02$ & $/ 0.323$ & $/ 0.328$ & $/ 0.076$ & \\
\hline$*$ Correlation is significant at the 0.05 level (2-tailed) \\
$* *$ Correlation is significant at the 0.01 level (2-tailed)
\end{tabular}

\section{Discussion}

Identification of human remains is a major challenge in every country. In an unidentified person, age estimation can apparently be done by some general features like height, weight, dental examination, secondary sexual characteristics etc. ${ }^{3,4}$ In the present study, we attempted to determine whether an association exists between the age and the stages of fusion of cranial (coronal, sagittal and lambdoid) sutures.

In the present study, we observed that the closure of sutures starts endocranially followed by ectocranial closure. Studies from other countries also support our observations. ${ }^{10-12}$ A study conducted by Patil et al., on 
150 human skulls concluded that suture closure is although not constant; however, it proceeds more quickly in endocranial sutures and reaches to a higher degree. ${ }^{14}$ Sahni et al., also observed that obliteration begins earlier on the endocranial surface. ${ }^{15}$

We observed that the process of sutural closure is more uniform and speedy in the endocranial sutures, thus, it is a more reliable parameter (for age determination) than ectocranial sutures. Almost all previous studies support our findings. Researchers ranging from Krogman et al., Todd and Lyon, and Patil T L (1981) have concluded that ectocranial fusion is less significant than endocranial fusion because suture along the outer table are more or less serrated while at dinner table they are comparatively straight, whereas the process is speedy and more uniform and complete in the endocranial surface. $6,10,14$,

In the present study, both ectocranially, as well as an endocranially sagittal suture, closes earlier followed by coronal and lambdoid suture. In the present study, it is found that although all the sutures show some degree of the lapsed union the ectocranial surface of sagittal suture is most common amongst the three whereas the study by Ulla et al., and Parmar et al., showed lapsed union in the coronal suture. ${ }^{16,17}$ A study by Ullas (2009) states that endocranially coronal suture closes earlier followed by sagittal and lambdoid and ectocranially sagittal suture closes earlier followed by lambdoid and coronal. ${ }^{16}$ These findings were correlated with the data are given by above-discussed researchers like years of age of starting of the union of the endocranial and ectocranial suture is total correlates with the years given in Todd and Lyon, Gaur et al., Sahai et al., Ullas (2009), Vijay kumar35. ${ }^{10,16-18}$ Workers like Pommerol et al., and Topinard also reported the same findings as comes in the present study though, their study does not indicate whether it was ectocranial or endocranial or it was commencement or termination. ${ }^{19,20}$

\section{Conclusion}

On the basis of our findings we make the following conclusions. Suture obliteration starts earlier on the endocranial surface than on the ectocranial.

For estimating the age of study subjects it is more appropriate to determine suture closure on the endocranial surface in comparison to the ectocranial surface. This is because suture along the outer table is more or less serrated while in the inner table they are comparatively straight, and the process is speedy and more uniform. In addition, closure of all three main sutures endocranially, start in 20-29 years of age in all sutures and complete closure attains at 40-49 years of age in the sagittal and coronal suture and in the lambdoid suture, it occurs at the age of 50-59 years. We observed that there was no significant variation in suture closure of right and left sides of coronal and lambdoid sutures, both ecto-cranially as well as endocranially.

\section{References}

1. Vij K. Textbook of Forensic Medicine \& Toxicology: Principles \& Practice-e-book. Elsevier Health Sciences. 2014; Feb 10.

2. Reddy NK, Murty OP. The essentials of forensic medicine and toxicology. Jaypee Brothers Medical Publishers; 2014.

3. Buchner A. The identification of human remains. International dental journal. 1985;Dec:35(4):307-11.

4. Deadman WJ. The identification of human remains. Canadian Medical Association journal. 1964;808(15): 10-91.

5. Sullivan KM, Hopgood R, Gill P. Identification of human remains by amplification and automated sequencing of mitochondrial DNA. International journal of legal medicine. 1992;105(2):83-6.

6. Krogman WM (1962) The Human Skeleton in Forensic Science. (1stedn), Springfield USA: Charles C. Thomas

7. Quigley C. Skulls and skeletons: Human bone collections and accumulations. McFarland; 2001.

8. Pritchard JJ, Scott JH, Girgis FG J.Anat.. The structure and development of cranial and facial sutures. 1956; 90(1):73-86.

9. Dwight T (1890). The closure of the cranial sutures as a sign of age. Boston Med Surg J. 1890;122:389-392.

10. Todd TW, Lyon DW (1924) Endocranial suture closure, its progress and age relationship. Part I-Adult males of the while stock. Am J Phys Anthropol 7: 325- 384.

11. Meindl RS, Lovejoy CO (1985) Ectocranial suture closure: a revised method for the determination of skeletal age at death based on the lateral-anterior sutures. Am J Phys Anthropol 68: 57-66.

12. Rahilly OR, Muller F, Carpenter S, Swenson R (1983) Basic Human Anatomy. (1stedn) London: WB Saunders, United Kingdom.

13. Singer R. Estimation of age from cranial suture closure. $J$ Forensic Med. 1953; 1: 52-9.

14. Patil TL, Bhargava, Qureshi AA. The study of cranial suture closure of the vault. J. Anat. Soc. of Ind. 1981; 308.

15. Sahni D, Jit I, Neelam, Sanjeev. Time of closure of cranial sutures in northwest Indian adults. Forensic science international. 2005 Mar 10; 148(2):199-205.

16. Shetty U. Macroscopic study of cranial suture closure at autopsy for estimation of age. Anil Aggrawal's Internet Journal of Forensic Medicine and Toxicology. 2009 July; 10(2).Availablefrom:http://www.anilaggrawal.com/ij/vol 010-no002/main.htm.

17. Gaur VB, Sahai VB, Singh A, Kharat A. Determination of age in living by closure of cranial sutures: A radiological study. Journal of Indian Academy of Forensic Medicine. 2007 Jan; 29(1):32-34.

18. Vijay Kumar AG, Agarwal SS, Bastia BK, Shivaramu MG, Honnungar RS. Fusion of Skull Vault Sutures in Relation to Age-A Cross-Sectional Postmortem Study Done in 3rd, 4th \& 5th Decades of Life. J Forensic Research. 2012; 3(10):173.

19. Pommerol F. Research on the synostosis of the bones of the skull: considered from the normal and pathological point of view in the different human races 1869.

20. Topinard P. The man in nature. Germer Baillière; 1891. 